\title{
ANALISIS KONSUMSI ENERGI LISTRIK DUA MOTOR INDUKSI TIGA FASA ANTARA TERHUBUNG LANGSUNG DENGAN TERHUBUNG TUKAR FASA
}

\author{
IG Suputra Widharma ${ }^{1}$, IM Sajayasa ${ }^{2}$, IN Sunaya ${ }^{3}$, IM Budiada ${ }^{4}$ \\ ${ }^{1} J u r u s a n$ Teknik Elektro Politeknik Negeri Bali Kampus Bukit Jimbaran, Kuta Badung, Bali \\ ${ }^{2}$ Jurusan Teknik Elektro Politeknik Negeri Bali Kampus Bukit Jimbaran, Kuta Badung, Bali \\ ${ }^{3} J u r u s a n$ Teknik Elektro Politeknik Negeri Bali Kampus Bukit Jimbaran, Kuta Badung, Bali \\ ${ }^{4} J u r u s a n$ Teknik Elektro Politeknik Negeri Bali Kampus Bukit Jimbaran, Kuta Badung, Bali \\ Email: suputra@pnb.ac.id; madesajayasa@pnb.ac.id; nengahsunaya@pnb.ac.id; budiada@pnb.ac.id
}

\begin{abstract}
Abstrak - Motor Induksi 3 fasa merupakan jenis motor yang paling banyak digunakan sebagai penggerak berbagai macam beban pada industri karena pengoperasian dan pemeliharaannya relatif mudah. Motor induksi digunakan mulai dari yang berkapasitas kecil sampai kapasitas besar. Untuk kapasitas di bawah $5 \mathrm{~kW}$ motor induksi tidak memerlukan alat bantu pengasutan alias dapat dihubungkan secara langsung dengan sumber 3 fasa yang dikenal dengan sistem DOL (direct on line).

Secara umum pengoperasian terhadap 2 motor induksi biasanya dilakukan dengan menghubungkan kedua motor induksi tersebut secara paralel pada satu kWh meter 3 fasa. Metode lain yang digunakan adalah kemungkinan kedua motor tersebut dicatu dari kWh meter tersendiri sehingga untuk dua motor tersebut menggunakan $2 \mathrm{kWh}$ meter.

Dalam penelitian akan ditinjau konsumsi pemakaian energy listrik pada 2 kondisi yang berbeda. Yang pertama dengan kondisi kedua motor disuplai dari satu $\mathrm{kWh}$ meter bersama, dan yang kedua masingmasing motor disuplai dari kWh meter tersendiri. Pengoperasian dua motor Induksi 3 Fasa dengan salah satu fasa ditukar konsumsi energinya lebih hemat dibandingkan dengan yang terhubung langsung. Dalam satu bulan terjadi penghematan sebesar $14.784 \mathrm{KWh}$ dengan asumsi motor beroperasi 8 jam sehari dengan 24 hari kerja sebulan.
\end{abstract}

Kata kunci : Motor induksi; kWh meter; fasa ditukar

\begin{abstract}
Three phase induction motor is a kind of motor that many using as operator in many variant of industries because easy to operate and maintenance. Induction motor is using since small capacity till big capacity. For capacity under $5 \mathrm{Kw}$, induction motor does not need trigger or can be contact directly to three phase supply that known by DOL (direct on line) system.

Generally operation of two induction motors usual by conjunction two induction motors parallel to one three phase KWH meter. Another method is using probability both of motors that supplied by $\mathrm{kWh}$ meter individually so that for two motors need two kWh meters.

In this research will be observed consumption of electric power in two different conditions. The first condition is two motors supplied by one kWh meter together, and the second every motor supplied by $k W h$ meter individually. Operation two induction motors of three phase with one of its phase changes its position has consumption power more efficient than contact directly. And in one month can be effective about $14.784 \mathrm{kWh}$ by assumption that motor operate 8 hours a day to 24 hours a month.
\end{abstract}

Keywords : induction motor; kWh motor; changing phase

\section{PENDAHULUAN}

Latar Belakang

Motor Induksi 3 fasa adalah jenis motor yang paling banyak digunakan di industri misalnya industri pengolahan kayu, tekstil, dan industri lainnya. Motor jenis ini disukai karena konstruksinya yang sederhana, dapat diandalkan, mudah perngoperasian dan perawatannya. Pada umumnya industri menggunakan banyak motor dengan kapasitas yang bervariasi dari kecil sampai besar sesuai dengan kebutuhan beban. Dalam pengoperasiannya, instalasinya motor-motor tersebut dapat dicatu secara sendiri-sendiri maupun berkelompok. Dalam pengoperasian motor berkelompok, motor-motor disuplai dari sumber PLN melalui satu kWh meter tiga fasa dengan urutan fasa yang sama (R,S,T dari sumber dengan $\mathrm{U}, \mathrm{V}, \mathrm{W}$ pada motor induksi). Namun demikian, dari hubungan antara sumber daya dengan beban, terdapat 
kemungkinan dua motor induksi yang dicatu secara terpisah melalui dua kWh meter, sedangkan salah satu fasanya ditukar [1], [2]

Dalam penelitian ini peneliti ingin mengamati apakah terdapat perbedaan dalam hal konsumsi energi listrik pada dua kelompok motor induksi yang sama bila disuplai secara berbeda. Konfigurasi pertama kedua motor disuplai secara paralel melalui satu $\mathrm{kWh}$ meter, sedangkan konfogurasi kedua kedua motor tersebut disuplai melalui dua $\mathrm{kWh}$ meter terpisah sedangkan salah satu fasanya ditukar. [3], [4]

Melalui pengamatan tersebut akan dapat dilihat perbedaan besar arus dan tegangan. Dengan mengamati kWh meter dapat pula dilihat perbandingan konsumsi energi listrik pada dua metode suplai di atas.

\section{Perumusan Masalah}

Berdasarkan uraian latar belakang penelitian, maka pokok rumusan masalah pada penelitian ini dapat dirangkum sebagai berikut:

1. Berapakah besarnya arus dan tegangan pada pengoperasian berkelompok (2 motor induksi) dengan satu $\mathrm{kWh}$ meter.?

2. Berapakah besarnya arus dan tegangan pada pengoperasian di mana setiap motor di atas disuplai melalui $\mathrm{kWh}$ meter terpisah dengan salah satu fasanya ditukar.?

3. Berapakah besarnya konsumsi energi listrik pada kedua metode pengoperasian motor induksi 3 fasa.?

\section{Tujuan dan Sasaran}

Adapun yang menjadi tujuan dilakukannya penelitian ini adalah sebagai berikut:

1. Untuk mengetahui besarnya arus dan tegangan pada kedua metode pengoperasian motor-motor tersebut.

2. Untuk mengetahui perbedaan konsumsi energi motor-motor tersebut dari kedua metode pengoperasian.

\section{TINJAUAN PUSTAKA Motor Induksi}

Motor dalam dunia kelistrikan ialah mesin yang digunakan untuk mengubah energi listrik menjadi energi mekanik. Salah satu motor listrik yang umum digunakan dalambanyak aplikasi ialah motor induksi. Motor induksi merupakan salah satu mesin asinkron (asynchronous motor) karena motor beroperasi dibawah kecepatan sinkron. [5]

Kecepatan sinkron sendiri ialah kecepatan rotasi medan magnetik pada motor .Kecepatan sinkron ini dipengaruhi oleh frekwensi motor dan banyak kutub pada motor. Motor induksi selalu berputar dibawah kecepatan sinkron karena medan magnet yang dibangkitkan pada stator akan menghasilkan fluks pada rotor sehingga rotor tersebut dapat berputar. Namun fluks yang terbangkitkan pada stator mengalami kertertinggalan dibandingkan fluks yang terbangkit pada stator sehingga kecepatan rotor tidak akan secepat kecepatan putaran medan magnet stator [6].

Motor Induksi dibedakan berdasarkan suplai di bagi dua : Motor Induksi satu fasa dan Motor Induksi 3 fasa. Dari kedua jenis motor ini yang membedakan adalah motor induksi satu fasa tidak bisa start sendiri sedangkan motor induksi 3 fasa bisa stats sendiri. Dalam penggunaannya Motor Induksi fasa lebih banyak digunakan dibandingkan Motor Induksi satu fasa [6], [7].

Motor induksi 3 fasa secara garis besar kontruksinya terdiri dari stator dan rotor. Stator adalah bagian yang diam dan rotor bagian yang berputar yang biasanya di kopel kebeban. Rotor dibagi lagi menjadi dua bagian yaitu rotor sangkat dan rotor belitan. Karena kontruksinya sangat sederhana maka pengoperasiannya dan pemeliharannya juga mudah. [8]

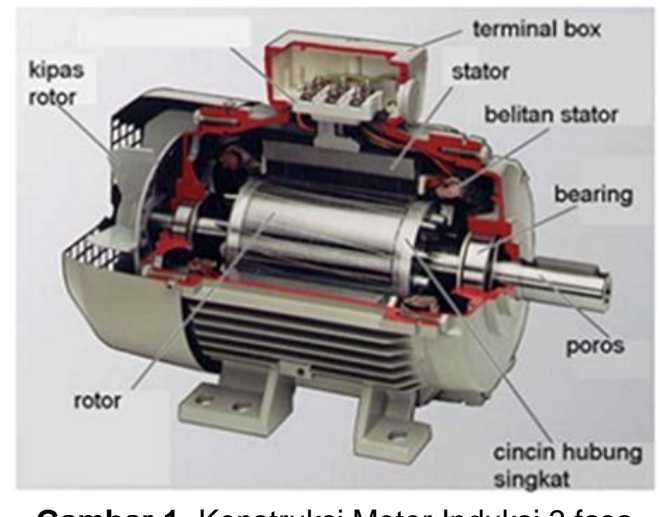

Gambar 1. Konstruksi Motor Induksi 3 fasa 


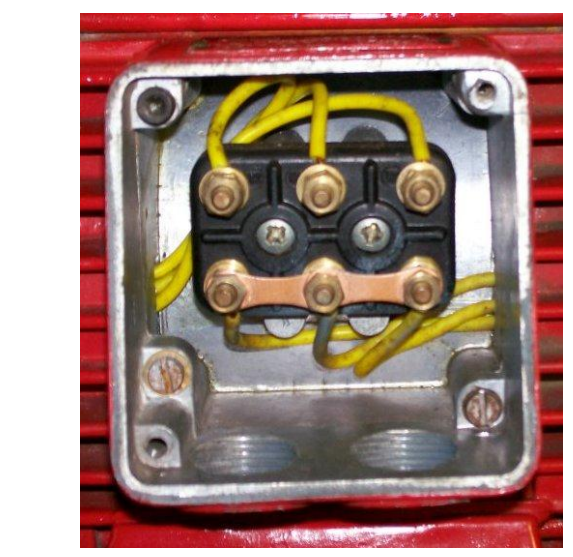

Gambar 2. Box terminal motor induksi 3 fasa

Penggunaan motor induksi 3 fasa paling banyak digunakan sebagai penggerak pada industri-industri. Pada pengoperasian motor induksi tiga fasa menurut (PUIL, 2000 ) kapasitas motor di bawah $5 \mathrm{KW}$ bisa dihubungkan langsung ke suplai (sistem DOL). Sedangkan yang dayanya diatas $5 \mathrm{KW}$ harus menggunakan alat bantu start, karena arus start motor induksi sangat besar $(2 \mathrm{~s} / \mathrm{d} 7 \mathrm{xI}$ ). [7], [8]

\section{METODE PENELITIAN Tempat dan Waktu Penelitian}

Penelitian akan dilakukan di Laboratorium Mesin Listrik Jurusan Teknik Elektro Kampus Politeknik Negeri Bali, Jl. Raya Kampus Bukit Jimbaran, Kuta Selatan, Badung-Bali. Penelitian ini direncanakan akan dilaksanakan selama delapan bulan.

\section{Sumber, Jenis dan Metode Pengumpulan Data}

Sumber data pada penelitian ini berupa data primer dan data sekunder. Data primer adalah data yang secara langsung dikumpulkan melalui pengukuran di lapangan maupun laboratorium. Data sekunder melihatkan berbagai pengetahuan dari berbagai buku bacaan maupun material yang dapat diunduh melalui internet.

Jenis data yang dikumpulkan berupa data kuantitatif. Data kuantitatif mencakup tingkat parameter listrik (tegangan, arus, dan sebagainya).

Metode pengumpulan data diantaranya sebagai berikut:

a. Metode wawancara

\section{b. Metode observasi}

\section{Rancangan Penelitian}

Rancangan penelitian diperlihatkan seperti pada Gambar 3.1.

Wiring diagram dua metode pengoperasian dua motor induksi 3 fasa yang satu menggunakan satu $\mathrm{KWh}$ dan yang satunya lagi menggunakan dua $\mathrm{KWh}$ meter.

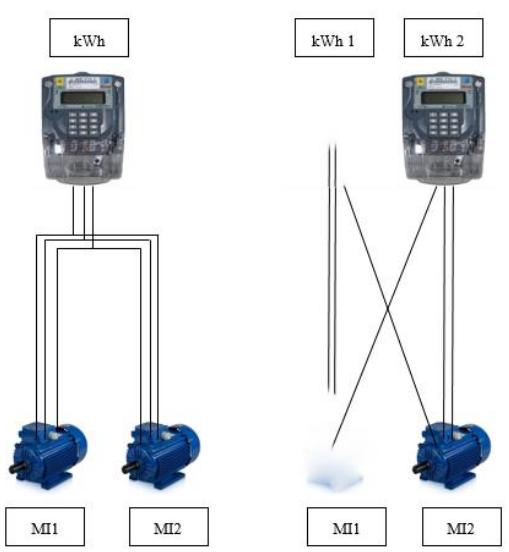

Gambar 3. Skematik Penelitian

\section{DATA HASIL DAN PEMBAHASAN Data Motor}

Data duaMotor Induksi yang digunakan dalam penelitian adalah sebagai berikut:

Motor Induksi 3 fasa

Daya $=1,1 \mathrm{KW}$ Tegangan $=380 / 400$ volt

Arus $=4,5 / 2,7$ AmpereCos $\mathrm{Q}=0,85$

Putaran $=1410 \mathrm{rpm}$.

\section{Data Hasil Percobaan}

Dalam melakukan pengambilan data peneliti melakukan 2 kali percobaan, yang pertama dua motor induksi dihubungkan langsung Kemudian yang kedua salah satu fasanya ditukar.

Tabel 1. Motor Induksi Terhubung Langsung

\begin{tabular}{|c|c|c|c|c|}
\hline $\begin{array}{c}\text { Motor } \\
\text { Induksi } \\
1\end{array}$ & Fasa & $\begin{array}{l}\text { Arus } \\
(\mathrm{A})\end{array}$ & $\begin{array}{c}\text { Tegangan } \\
\text { (volt ) }\end{array}$ & CosQ \\
\cline { 2 - 5 } & $\mathrm{U}$ & 1,9 & 220 & 0,85 \\
\cline { 2 - 5 } & $\mathrm{V}$ & 1,9 & 220 & 0,85 \\
\cline { 2 - 5 } & $\mathrm{W}$ & 1,5 & 220 & 0,85 \\
\hline
\end{tabular}

\begin{tabular}{|c|c|c|c|c|}
\hline $\begin{array}{c}\text { Motor } \\
\text { Induksi }\end{array}$ & Fasa & $\begin{array}{c}\text { Arus } \\
\text { (A) }\end{array}$ & $\begin{array}{c}\text { Tegangan } \\
\text { (volt ) }\end{array}$ & CosQ \\
\cline { 2 - 5 } 2 & $\mathrm{U}$ & 1,9 & 220 & 0,85 \\
\cline { 2 - 5 } & $\mathrm{V}$ & 1,9 & 220 & 0,85 \\
\cline { 2 - 5 } & $\mathrm{W}$ & 1,5 & 220 & 0,85 \\
\hline
\end{tabular}


Tabel 2. Motor Induksi Salah Satu Fasa Ditukar

\begin{tabular}{|c|c|c|c|c|}
\hline $\begin{array}{c}\text { Motor } \\
\text { Induksi }\end{array}$ & Fasa & $\begin{array}{l}\text { Arus } \\
(\mathrm{A})\end{array}$ & $\begin{array}{c}\text { Tegangan } \\
\text { (volt ) }\end{array}$ & CosQ \\
\cline { 2 - 5 } & $\mathrm{U}$ & 1,51 & 220 & 0,85 \\
\cline { 2 - 5 } & $\mathrm{V}$ & 1,80 & 220 & 0,85 \\
\cline { 2 - 5 } & $\mathrm{W}$ & 1,80 & 220 & 0,85 \\
\hline
\end{tabular}

\begin{tabular}{|c|c|c|c|c|}
\hline $\begin{array}{c}\text { Motor } \\
\text { Induksi }\end{array}$ & Fasa & $\begin{array}{c}\text { Arus } \\
(\mathrm{A})\end{array}$ & $\begin{array}{c}\text { Tegangan } \\
\text { (volt ) }\end{array}$ & CosQ \\
\cline { 2 - 5 } 2 & $\mathrm{U}$ & 1,5 & 220 & 0,85 \\
\cline { 2 - 5 } & $\mathrm{V}$ & 1,76 & 220 & 0,85 \\
\cline { 2 - 5 } & $\mathrm{W}$ & 1,82 & 220 & 0,85 \\
\hline
\end{tabular}

\section{Pembahasan}

Untuk mendapatkan daya yang dipakai motor digunakan rumus :

$$
P=V X I X \cos Q
$$

Contoh perhitungan dari Tabel 4-1 untuk fasa $\mathrm{V}$, arus $=1,9 \mathrm{~A}, \mathrm{~V}=220$ Volt dan $\cos Q=0,85$ maka dayanya :

$$
P=1,9 \times 220 \times 085 \quad P=355,3 \text { watt. }
$$

Dengan cara yang sama dapat dilihat dalam Tabel 4-3 hingga Tabel 4-6.

Tabel 3. Daya Motor Induksi 1Terhubung Langsung

\begin{tabular}{|c|c|c|c|c|c|}
\hline $\begin{array}{c}\text { Motor } \\
\text { Induksi } \\
1\end{array}$ & Fasa & $\begin{array}{l}\text { Arus } \\
(\mathrm{A})\end{array}$ & $\begin{array}{c}\text { Tegangan } \\
\text { (volt ) }\end{array}$ & CosQ & $\begin{array}{c}\text { Daya } \\
\text { (watt) }\end{array}$ \\
\cline { 2 - 6 } & $\mathrm{U}$ & 1,9 & 220 & 0,85 & 355,3 \\
\cline { 2 - 6 } & $\mathrm{V}$ & 1,9 & 220 & 0,85 & 355,3 \\
\cline { 2 - 6 } & $\mathrm{W}$ & 1,5 & 220 & 0,85 & 280,5 \\
\hline
\end{tabular}

Tabel 4. Daya Motor Induksi 2 terhubung Langsung

\begin{tabular}{|c|c|c|c|c|c|}
\hline $\begin{array}{c}\text { Motor } \\
\text { Induksi } \\
2\end{array}$ & Fasa & $\begin{array}{c}\text { Arus } \\
(\mathrm{A})\end{array}$ & $\begin{array}{c}\text { Tegangan } \\
\text { (volt ) }\end{array}$ & CosQ & $\begin{array}{c}\text { Daya } \\
\text { (watt) }\end{array}$ \\
\cline { 2 - 6 } & $\mathrm{U}$ & 1,9 & 220 & 0,85 & 355,3 \\
\cline { 2 - 6 } & $\mathrm{V}$ & 1,9 & 220 & 0,85 & 355,3 \\
\cline { 2 - 6 } & $\mathrm{W}$ & 1,5 & 220 & 0,85 & 280,5 \\
\hline
\end{tabular}

Tabel 5. Daya Motor Induksi 1Salah Satu Fasa Ditukar

\begin{tabular}{|c|c|c|c|c|c|}
\hline $\begin{array}{c}\text { Motor } \\
\text { Induksi } \\
1\end{array}$ & Fasa & $\begin{array}{l}\text { Arus } \\
(\mathrm{A})\end{array}$ & $\begin{array}{c}\text { Tegangan } \\
\text { (volt ) }\end{array}$ & CosQ & $\begin{array}{c}\text { Daya } \\
\text { (watt) }\end{array}$ \\
\cline { 2 - 6 } & $\mathrm{U}$ & 1,51 & 220 & 0,85 & 282,4 \\
\cline { 2 - 6 } & $\mathrm{V}$ & 1,80 & 220 & 0,85 & 336,6 \\
\cline { 2 - 6 } & $\mathrm{W}$ & 1,80 & 220 & 0,85 & 336,6 \\
\hline
\end{tabular}

Tabel 6. Daya Motor Induksi 2 Salah Satu Fasa Ditukar

\begin{tabular}{|c|c|c|c|c|c|}
\hline $\begin{array}{c}\text { Motor } \\
\text { Induksi } \\
2\end{array}$ & Fasa & $\begin{array}{l}\text { Arus } \\
(\mathrm{A})\end{array}$ & $\begin{array}{c}\text { Tegangan } \\
\text { (volt ) }\end{array}$ & CosQ & $\begin{array}{c}\text { Daya } \\
\text { (watt) }\end{array}$ \\
\cline { 2 - 6 } & $\mathrm{U}$ & 1,50 & 220 & 0,85 & 280,5 \\
\cline { 2 - 6 } & $\mathrm{V}$ & 1,76 & 220 & 0,85 & 329,1 \\
\cline { 2 - 6 } & $\mathrm{W}$ & 1,82 & 220 & 0,85 & 340,3 \\
\hline
\end{tabular}

\section{Konsumsi Energi}

Perhitungan daya

Dua Motor Induksi yang terhubung langsung.

$P=355,3+355,3+280,5+355,3+355,3+280,5$

$\mathrm{P}=1.982,2$ watt

Dua Motor Induksi yang salah satu fasa ditukar

$P=282,4+336,6+336,6+280,5+329,1+340,3$

$\mathrm{P}=1.905,5$ watt

Selisih konsumsi daya

$P=1982,2-1905,5$

$\mathrm{P}=76,7$ watt

\section{Perhitungan energi}

Rumus yang dipakai dalam perhtungan energi listrik adalah daya dikalikan waktu.

$\mathrm{KWH}=\mathrm{KW} \times \mathrm{t}$

Jika diasumsikan dalam sehari motor beroperasi 8 jam dan hari kerja dalam satu bulan 24 hari maka konsumsi energi dua metode pengoperasian 2 motor induksi sebagai berikut :

Dua motor induksi terhubung langsung

$$
\begin{aligned}
& \mathrm{Pe}=1982,5 \times 8 \times 24 \\
& \mathrm{Pe}=380.640 \mathrm{KWH}
\end{aligned}
$$

Dua motor induksi yang salah satu fasa ditukar

$$
\begin{aligned}
& \mathrm{Pe}=1905,5 \times 8 \times 24 \\
& \mathrm{Pe}=365.856
\end{aligned}
$$

Selisih konsumsi energi

$$
\begin{aligned}
& \mathrm{Pe}=380.640-365.856 \\
& \mathrm{Pe}=14.784 \mathrm{KWH}
\end{aligned}
$$

Jadi dari hasil analisa data diatas pengoperasian dengan metode salah satu fasa ditukar terjadi penghematam energi listrik sebesar $14.784 \mathrm{KWH}$ per bulan

\section{SIMPULAN}

Pengoperasian dua Motor Induksi 3 Fasa dengan salah satu fasa ditukar konsumsi energinya lebih hemat dibandingkan dengan yang terhubung langsung.

Dalam satu bulan terjadi penghematan sebesar $14.784 \mathrm{KWh}$ dengan asumsi motor 
beroperasi 8 jam sehari dengan 24 hari kerja sebulan.

\section{DAFTAR PUSTAKA}

A.F. Puchstein, T.C. Lloyd, A.E. Conrad, 1972. Alternating Current Machines, Edisi Ketiga, Modern Asia Edition, John Wiley \& Sons Inc.

Fitzgerald, A.E. Mesin Mesin Listrik, Edisi Keempat, terjemahan Achyanto, Jakarta, Erlangga.

Lister, Eugene C., 1988. Mesin dan Rangkaian Listrik, Edisi Keenam, terjemahan Ir. Drs. Hanapi Gunawan, Jakarta, Erlangga.

Malik, IA, Nasrun H, Syahrial. 2013. Analisi Penghematan Energi Motor Listrik di PT.X. Jurnal Reka Elkomnika vol. 1 (3)
Soelaiman, Prof. Ts. MHD, Magarisawa, Mabuchi. 1984. Mesin Tak Serempak Dalam Praktek. Jakarta, PT. Pradnya Paramita.

Sajayasa, IM, IG Suputra Widharma, IK Amerta Yasa. 2008. Performansi Motor Induksi Tiga Phasa pada Kondisi Operasi Satu Phasa dalam Perspektif Neuro Fuzzy Analisis. Jurnal Teknologi Elektro vol. 7 (1)

Suputra Widharma, IG, IM Sajayasa. 2016. Penjadwalan Waktu Beban Kerja Dengan Metode Algoritma Active Schedule Dan Heuristic Schedule Untuk Efisiensi Daya Listrik. Matrix 4 (1)

Zuhal, 1982. Dasar Tenaga Listrik, Bandung, ITB. 